\title{
Behavioral deficits in a rat model of maternal PKU
}

\author{
ANN T. HANULAK \\ Calasanctius Preparatory School, Buffalo, New York \\ and \\ ELAINE M. HULL \\ State University of New York at Buffalo, Amherst, New York
}

\begin{abstract}
Phenylketonuria was experimentally induced in one group of pregnant rats by supplementing their diets with $\alpha$-methylphenylalanine and phenylalanine on Days 10-21 of gestation. Control groups were either pair fed or ad-lib fed. Offspring of the drug-treated mothers were deficient on several measures of swimming development, active avoidance acquisition, and initiation of masculine sexual behavior. This experimental model of maternal PKU has been shown to exhibit fewer toxic effects than earlier models. The fact that the treatment induced enduring behavioral deficits, over and above deficits related to lower maternal food intake, suggests that this model is a useful one for studying the biochemical mechanisms of and treatment for maternal PKU.
\end{abstract}

Phenylketonuria (PKU) is an inherited disease causing severe mental retardation and other manifestations of brain damage. Mental retardation not only is associated with classic or homozygous PKU, but is also found in most heterozygous infants of phenylketonuric mothers (Lenke \& Levy, 1980). Since dietary treatment of children with classic PKU has resulted in an increased number of PKU females reaching childbearing age, there is a need for more information concerning the developmental processes affected by maternal, as well as classic, PKU.

Biochemically, PKU is characterized by a deficit in the normal conversion of phenylalanine to tyrosine, which results in a surplus of phenylalanine and in other related biochemical changes. Earlier animal models of this disease employing phenylalanine in combination with parachloro-phenylalanine produced toxic side effects and death (Anderson, 1976; Copenhaver, Carver, \& Schalock, 1974). A recent animal model of maternal PKU utilized increased dietary phenylalanine together with $\alpha$-methylphenylalanine, which resulted in fewer toxic side effects than phenylalanine with para-chloro-phenylalanine (Brass, Isaacs, McHesney, \& Greengard, 1982). This drug regimen resulted in a 5-10 fold increase in brain phenylalanine of treated fetuses, compared with that of controls. Since no single experimental model of PKU exactly replicates the biochemical environment of PKU, it would be advantageous to compare different models, each of which

This research was submitted by Ann T. Hanulak in partial fulfillment of requirements for graduation from Calasanctius Preparatory School. Elaine M. Hull was adviser for the project. The authors' mailing address is Department of Psychology, State University of New York at Buffalo, Park Hall, Amherst, NY 14260. Reprint requests should be addressed to Elaine $\mathbf{M}$. Hull at that address. is characterized by elevated levels of phenylalanine, but which differ in other respects.

Chronic neonatal administration of $\alpha$-methylphenylalanine has been found to produce various learning deficits in adulthood (Greengard, Dienal, \& DelValle, 1979; Lane, Schone, Langenbeck, \& Neuhoff, 1979; Luttges \& Gerren, 1979; Strupp, Levitsky, \& Blumstein, 1984), suggesting that this neonatal regimen may be a useful model of classic PKU. However, none of these studies controlled for nutritional deficiencies due to drug-induced suppression of appetite. To date there have been no studies of behavioral effects of prenatal treatment with the $\alpha$ methylphenylalanine plus phenylalanine regimen as a model of maternal PKU.

The present study was designed to test the development of several behavioral patterns following maternal $\alpha$ methylphenylalanine plus phenylalanine treatment during pregnancy. Since experimental elevation of phenylalanine levels is usually accompanied by decreased appetite (Vorhees, Butcher, \& Berry, 1981), pair-fed and ad-libfed control groups were included to determine the relative contributions of the drug, per se, and of decreased maternal food consumption to producing any behavioral changes.

\section{METHOD}

\section{Subjects}

Ten female Long-Evans rats were time-mated with males of the same strain. The subjects were their 116 male and female offspring. There were 49 drug-treated offspring from four litters, although 4 pups died on Postnatal Day 20. Four pair-fed litters contributed 41 animals; and two ad-lib-fed litters contributed 26 animals. Lights were on from 0800 to 2000 . 
The female subjects were fed Agway rat pellets until Gestation Day 10 . At this time 4 of the animals' diets were supplemented with $0.5 \% \alpha$-methyl-D,L-phenylalanine and $3 \%$ phenylalanine (Brass et al., 1982). The drugs were premixed with ground rat chow and refrigerated. On Gestation Day 10,25 $\mathrm{g}$ of the food and drug mixture was combined with an equal amount of water (to minimize spillage) and fed to females in the drug group. Twenty-four hours later the food was weighed and the amount eaten was recorded. In order to control for nutritional factors, each pair-fed female was matched to 1 drug-treated female and received a ration each day that was equal in weight to the amount consumed by the matched drug-treated animal on the equivalent day of her gestation. The pairfed animals' food was prepared and weighed in the same manner as for the drug-treated animals, except that the drug was not added. Two litters were ad-lib fed rat chow pellets throughout gestation.

Pups were weighed at 6,18 , and 70 days of age. On Postnatal Day 30, dams were removed. After completion of swimming tests (Postnatal Day 40), litters were culled to 4 males and 3 females. Three of the 4 males (randomly selected) and the 3 females from each litter were tested for active avoidance performance; the 4 males from each litter were retained for sexual behavior tests. (One litter had only 2 males.)

\section{Apparatus}

Swimming tests were conducted in a basin measuring $46 \times 56 \mathrm{~cm}$, filled to a depth of $26 \mathrm{~cm}$ with water at $27^{\circ} \mathrm{C}$. A Lehigh Valley operant conditioning module $(26 \times 20 \mathrm{~cm})$ was used for active avoidance tests. A piece of Plexiglas $(19 \times 13 \mathrm{~cm})$ covered half the grid floor; shock $(.4 \mathrm{~mA})$ was administered to the uncovered half of the floor. Sex behavior tests were conducted in the males' home cages $(24 \times 46 \times 21 \mathrm{~cm})$.

\section{Procedure}

Swimming tests. On Postnatal Day 6, each pup was placed gently in the water and graded on its head angle relative to the water surface, direction of movement, latency to begin moving, and front leg activity (see Adams, 1982; Schapiro, Salas, \& Vukovich, 1970). For head angle, a score of 0 indicated head below the surface; 1 , top of head at surface but nose under surface; 2 , nose out; 3 , ears half out; and 4, ears out of the water. For direction, 0 indicated sinking; 1, floating; 2, circling; and 3, swimming straight. Front paw movement was rated from 0 (no movement) to 4 (vigorous movement). (Suppression of front paw movement is characteristic of the adult swimming pattern.) Pups received 3 trials per day, 5-15 sec per trial and approximately $20 \mathrm{sec}$ apart. Scores for the trials were averaged. All the pups from each litter were tested every other day until all of them had perfect scores $(4,3$, and 0 , respectively, on the three measures) or until $\mathbf{4 0}$ days of age, whichever came first. Kruskal-Wallis one-way analysis of variance by ranks was used to compare litter means for each measure.

Active avoidance tests. At approximately 45 days of age, 3 males and 3 females from each litter were given 2 days of active avoidance testing. On each acquisition trial a pup was placed in the apparatus facing away from the sheet of Plexiglas covering the opposite half of the grid floor. After $7 \mathrm{sec}$ a .4-mA shock was applied to the floor. If the pup failed to reach the Plexiglas within $20 \mathrm{sec}$ after shock onset, it was placed on the Plexiglas and the shock was terminated. If the animal reached the Plexiglas within the first $7 \mathrm{sec}$, it successfully avoided shock on that trial. Latency to escape or avoid the shock on each trial was measured with a stopwatch. For the 20 -sec intertrial interval, the animal was placed in a plastic cage with sawdust on the bottom. Each animal received at least 15 acquisition trials, but no more than 30 , on Testing Day 1 , with acquisition trials being terminated after a criterion of five successive avoidance responses. On the following day, 5 additional acquisition trials were administered, followed by 10 extinction trials with no shock. Latencies to reach the Plexiglas were averaged over blocks of 5 trials on each day, and were compared by analysis of variance, utilizing Winer's (1971) and Denenberg's (1984) method of preliminary testing for nested (litter) factors. (Since equal numbers of litters per group are required for analysis of nested factors, and since $t$ tests revealed no significant differences between pair-fed and ad-lib-fed control groups, the drug-treated group was compared only with the pair-fed control group.)

Male sexual behavior. At 65 days of age, 4 males from each litter were given their first test of sexual behavior. Tests were conducted in the male's large plastic home cage, under dim illumination, approximately $2 \mathrm{~h}$ after lights were turned out. Ovariectomized stimulus females were brought into estrus by an injection of $10 \mu \mathrm{g}$ estradiol benzoate $48 \mathrm{~h}$ before testing, followed by $.5 \mathrm{mg}$ progesterone $4 \mathrm{~h}$ before the test. This hormone regimen reliably induces both receptive and proceptive (hopping and darting) feminine behavior. Each test began with placement of the female into the male's cage and lasted for $30 \mathrm{~min}$ after his first intromission, or for $30 \mathrm{~min}$ after introduction of the female if the male failed to intromit. Latencies to each mount, intromission, and ejaculation were recorded. Mounts were characterized by clasping of the female's flanks and pelvic thrusting. Mounts with intromissions were distinguished from those without by the presence of a rapid, springing dismount. Mounts with ejaculations were characterized by a final deep thrust and a slow dismount, and were followed by a 5-15 min period of rest. Several additional measures were derived, including intromission frequency (number of intromissions preceding the first ejaculation), intromission ratio (number of intromissions/sum of mounts plus intromissions), interintromission interval (mean seconds between intromissions preceding the first ejaculation), and postejaculatory interval (latency to the first intromission after each ejaculation). At 75 days of age, males received their second sexual behavior test, using the same procedure. Since $t$ tests again revealed no differences between the two control groups, drug-treated and pair-fed control animals were compared using the nested factors design. (One pair-fed litter had only 2 males; therefore, in order to obtain equal numbers of subjects, one ad-lib-fed litter was substituted for it.)

\section{RESULTS}

\section{Litter Size and Body Weight}

There were no significant differences in litter size among the three groups. Drug-treated dams gave birth to an average of 12 pups; pair-fed dams, to 10 ; and adlib-fed dams, to 13. Significant body weight differences were evident on Postnatal Day 6, with ad-lib-fed pups being heaviest; pair-fed and drug-treated animals did not differ in weights (see Table 1). Weight differences were no longer significant at 18 and 70 days.

\section{Swimming Development}

Drug-treated and, to a lesser extent, pair-fed pups were delayed on several measures of swimming development, compared with ad-lib-fed controls (see Table 2). On Post-

Table 1

Body Weight

\begin{tabular}{|c|c|c|c|c|c|c|c|}
\hline & \multicolumn{2}{|c|}{ Day 6} & & \multicolumn{2}{|c|}{ Day 18} & \multicolumn{2}{|c|}{ Day 70} \\
\hline & Mean & $S E M$ & & Mean & $S E M$ & Mean & SEM \\
\hline$\overline{\text { Drug }}$ & 10.0 & 0.1 & & 27.1 & 0.3 & 386.8 & 7.6 \\
\hline Pair Fed & 10.5 & 0.17 & + & 30.3 & 0.4 & 396.3 & 7.8 \\
\hline Ad-lib Fed & 11.9 & $0.1 \mathrm{~J}$ & & 32.4 & 0.7 & 401.3 & 8.1 \\
\hline
\end{tabular}

Note--Comparisons used Kruskal-Wallis tests on litter means, corrected for ties. Day 6, $H=7.41, p<.01$; Day $18, H=4.56$, n.s.; and Day $70, H=1.26$, n.s. Day 70 data were from males undergoing sex behavior tests. ${ }^{*} p<.01$. 
Table 2

Swimming Measures, Significant Effects

\begin{tabular}{|c|c|c|c|c|c|c|c|c|}
\hline & \multicolumn{4}{|c|}{ Head Angle } & \multirow{2}{*}{\multicolumn{2}{|c|}{$\frac{\text { Direction }}{\text { Day } 18}$}} & \multirow{2}{*}{\multicolumn{2}{|c|}{$\frac{\text { Front-Paw Movement }}{\text { Day } 20}$}} \\
\hline & \multirow{2}{*}{\multicolumn{2}{|c|}{$\frac{\text { Day } 10}{\text { Mean } S E M}$}} & \multirow{2}{*}{\multicolumn{2}{|c|}{$\frac{\text { Day } 12}{\text { Mean SEM }}$}} & & & & \\
\hline & & & & & Mean & $S E M$ & Mean & SEM \\
\hline d-lib Fed & $\begin{array}{l}1.78 \\
1.98 \\
2.30\end{array}$ & $\left.\begin{array}{l}.06 \\
.66 \\
.09\end{array}\right]$ & $\begin{array}{r}2.42 \\
* \quad 2.64 \\
2.96\end{array}$ & $\begin{array}{l}0.7 \\
0.06 \\
0.06\end{array}$ & $\begin{array}{l}2.67 \\
2.85 \\
3.00\end{array}$ & $\left.\begin{array}{l}.05 \\
.04 \\
.00\end{array}\right]$ & $\begin{array}{l}2.80 \\
1.52\end{array}$ & $\left.\begin{array}{l}.12 \\
.13 \\
.22\end{array}\right] *$ \\
\hline
\end{tabular}

Note-Comparisons used Kruskal-Wallis tests on litter means, corrected for ties. Head angle, Day $10, H=5.56, p<.05$; head angle, Day $12, H=5.41, p<.05$; direction, Day 18, $H=5.48, p<.05$; front-paw movement, Day $20, H=5.76, p<.05$. $*_{p}<.05$.

natal Days 10 and 12 , the ad-lib-fed control pups exhibited the highest head position in the water, and drug animals exhibited the lowest; pair-fed animals had intermediate scores that were not significantly different from those of either of the other groups. On Postnatal Day 18 the same relationship among groups was observed for direction of swimming. Similarly, front-paw movement suppression began to occur earliest in ad-lib-fed controls, which differed significantly on Day 20 from both drug-treated and pair-fed groups.

\section{Active Avoidance}

Drug-treated animals exhibited longer latencies to respond in Blocks $B$ and $C$ of acquisition on Testing Day 1 of the active avoidance task, and in Block A (acquisition, shock present) on Testing Day 2, immediately prior to extinction testing (see Table 3). Furthermore, they required more trials to reach the criterion of five consecutive avoidances. There were no significant differences in response latencies on the extinction trials of Day 2 (without shock).

\section{Sexual Behavior Tests}

Drug-treated animals were slower than controls to begin copulating on both tests (see Table 4). There were no significant differences between drug-treated and control animals on other copulatory measures. Thus the only drug-related deficit was a delay in onset of copulation, and there was no deficit in achieving ejaculation once copulation had begun.

\section{DISCUSSION}

Prenatal maternal treatment with $\alpha$-methylphenylalanine plus phenylalanine resulted in impairments of the offspring on several behavioral tests beginning at 10 days of age and continuing well into adulthood. These impairments included retardation of some aspects of motor (swimming) development, learning deficits on an active avoidance task, and delayed initiation of copulation with a receptive female.

Swimming development has been shown to be sensitive to several neonatal treatments, including cortisol and thyroxine (Schapiro et al., 1970), chlordiazepoxide (Adams, 1982), and alterations of catecholamine levels (Tamasy, Koranyi, \& Phelps, 1981). The present experiment demonstrates that prenatal hyperphenylalaninemia can also alter several measures of swimming development. However, the drug-treated group's performance was statistically different only from that of the ad-lib-fed group on these measures; the pair-fed group did not differ from either (except for the Postnatal Day 20 paw suppression). Thus, it is the combination of the drug effect, per se, and the associated nutritional impairment that retarded swimming development.

Drug-treated animals exhibited longer latencies to move onto the Plexiglas during active avoidance tests, and also required more trials to reach the criterion of five successive avoidances. Although locomotor activity was not specifically measured, behavioral observations of the animals during acquisition trials suggested that those in the drugtreated group were not hypoactive. Control animals learned in relatively few trials to move quickly to the Plexiglas-covered area of safety, whereas drug-treated animals repeatedly jumped up against the nearest walls of the apparatus. Although this strategy produced very brief escapes from the shock, it was not effective in producing longer term escape or avoidance. Thus the behavioral deficit in this task appeared to be related more to fixation on an ineffective behavior than to hypoactivity.

Table 3

Active Avoidance, Significant Effects

\begin{tabular}{|c|c|c|c|c|c|c|c|c|c|c|c|c|}
\hline \multirow[b]{3}{*}{ Group } & \multicolumn{9}{|c|}{ Day 1} & \multirow{2}{*}{\multicolumn{2}{|c|}{$\begin{array}{c}\text { Day } 2 \\
\text { Block A }\end{array}$}} & \\
\hline & \multicolumn{2}{|c|}{ Block B } & & \multicolumn{2}{|c|}{ Block C } & \multicolumn{3}{|c|}{ Criterion Trial } & & & & \\
\hline & Mean & $S E M$ & & Mean & $S E M$ & & Mean & $S E M$ & & Mean & SEM & \\
\hline $\begin{array}{l}\text { Drug } \\
\text { Pair Fed } \\
\text { Ad-lib Fed }\end{array}$ & $\begin{array}{l}7.5 \\
4.1 \\
4.3\end{array}$ & $\left.\begin{array}{l}1.0 \\
0.05 \\
1.2\end{array}\right]$ & $\left\{\begin{array}{c}* \\
\text { n.s. }\end{array}\right.$ & $\begin{array}{l}5.0 \\
2.5 \\
2.3\end{array}$ & $\left.\begin{array}{l}0.8 \\
0.03 \\
0.7\end{array}\right]$ & $\begin{array}{c}\dagger \\
\text { n.s. }\end{array}$ & $\begin{array}{l}17.0 \\
11.5 \\
12.3 \\
\end{array}$ & $\left.\begin{array}{l}1.5 \\
0.6 \\
1.2\end{array}\right]$ & $\begin{array}{c}\ddagger \\
\text { n.s. }\end{array}$ & $\begin{array}{l}7.0 \\
4.6 \\
4.0\end{array}$ & $\left.\begin{array}{l}0.8 \\
0.5 \\
0.6\end{array}\right]$ & $\begin{array}{c}\S \\
\text { n.s. }\end{array}$ \\
\hline
\end{tabular}


Table 4

Male Sexual Behavior, Significant Effects

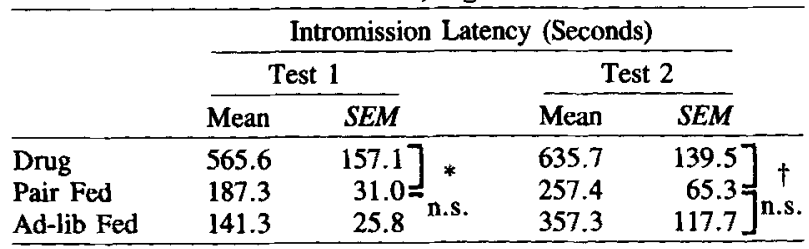

$* F(1,30)=6.72$, using pooled error term, $p<.05 . \dagger F(1,30)=4.72$, using pooled error term, $p<.05$.

The only drug-related deficit in sexual behavior tests was a delay in the onset of copulation (increased intromission latency). Once drug-treated animals began copulating, their behavior was not significantly different from that of controls. Beach (1956) proposed that masculine sexual behavior is composed of at least two factors, an arousal mechanism leading to the onset of copulation and a copulatory mechanism that sums the effects of repeated intromissions until an ejaculation is triggered. It is the arousal factor that was impaired by the current prenatal $\alpha$-methylphenylalanine plus phenylalanine treatment. This result contrasts with the effects of perinatally administered dopamine-related drugs, which produced deficits in the hypothetical copulatory mechanism, but not in sexual arousal (Hull, Nishita, Bitran, \& Dalterio, 1984).

In summary, maternal administration of $\alpha$-methylphenylalanine plus phenylalanine during pregnancy resulted in several kinds of behavioral deficits in the offspring, beginning at 10 days of age and continuing well into adulthood. In the tests of swimming development, both the drug, per se, and nutritional deprivation resulting from appetite suppression appeared to produce additive effects. This finding underscores the importance of using nutritional controls in tests of animal models of PKU. On the other hand, the deficits in active avoidance and in sexual arousal appear to have resulted from the drug, per se. It is not clear whether the lack of nutritional effects on these measures was due to the longer time since the drug treatment or to the different requirements of these tests. Maternal treatment with $\alpha$-methylphenylalanine plus phenylalanine during gestation has resulted in enduring behavioral deficits in the offspring; therefore, this regimen appears to produce a useful model of maternal PKU, which may be used in the search for more effective treatments for this disorder.

\section{REFERENCES}

Adams, P. M.(1982). Effects of perinatal chlordiazepoxide exposure on rat preweaning and postweaning behavior. Neurobehavioral Toxicology \& Teratology, 4, 279-282.

ANDERSON, A. (1976). Maternal hyperphenylalanemia: An experimental model in rats. Developmental Psychobiology, 9, 157-166.

BEACH, F. A. (1956). Characteristics of masculine "sex drive." In $M . R$. Jones (Ed.), Nebraska Symposium on Motivation (Vol. 4, pp. 1-32). Lincoln: University of Nebraska Press.

Brass, C. A., Isaacs, C. E., McHesney, R., \& Greengard, O. (1982). The effects of hyperphenylalanemia on fetal development: A new animal model of maternal phenylketonuria. Pediatric Research, 16, 388-394.

Copenhaver, J. H., Carver, M. J., \& Schalock, R. L. (1974). Experimental maternal hyperphenylalaninemia: Biochemical effects and offspring development. Developmental Psychobiology, 7, 175-184.

DenenBerg, V. H. (1984). Some statistical and experimental considerations in the use of the analysis-of-variance procedure. American Journal of Physiology, 246, R403-R408.

Greengard, O., Dienal, G., \& DelValle, J. (1979). The induction and consequences of severe hyperphenylalaninemia in infant rats. In F. A. Hommes (Ed.), Models for the study of inborn errors of metabolism (pp. 59-73). Amsterdam: Elsevier/North Holland.

Hull, E. M., Nishita, J. K., Brtran, D., \& Dalterio, S. (1984). Perinatal dopamine-related drugs demasculinize rats. Science, 224, 1011-1013.

Lane, J. D., Schone, B., LANGenbeck, U., \& Neuhoff, V. (1979). Characterization of experimental phenylketonuria. In F. A. Hommes (Ed.), Models for the study of inborn errors of metabolism (pp. 141148). Amsterdarn: Elsevier/North Holland.

Lenke, R. R., \& Levy, H. L. (1980). Maternal phenylketonuria and hyperphenylalanemia. An international survey of the outcome of untreated and treated pregnancies. New England Joumal of Medicine, $303,1202-1208$

LUTTGES, M. W., GerReN, R. A. (1979). Postnatal $\alpha$-methylphenylalanine treatment effects on adult locomotor activity and avoidance learning. Pharmacology, Biochemistry \& Behavior, 11, 493-498.

Schapiro, S., Salas, M., \& VuKovich, K. (1970). Hormonal effects on ontogeny of swimming ability in the rat: Assessment of central nervous system development. Science, 168, 147-151.

Strupp, B. J., Levrtsky, D. A., \& Blumstein, L. (1984). PKU, learning, and models of mental retardation. Developmental Psychobiology, 17, 109-120.

Tamasy, V., Koranyi, L., \& Phelps, C. P. (1981). The role of dopaminergic and serotonergic mechanisms in the development of swimming ability of young rats. Developmental Neuroscience, 4, $389-400$.

Vorhees, C. V., Butcher, R. E., \& Berry, H. K. (1981). Progress in experimental phenylketonuria: A critical review. Neuroscience \& Biobehavioral Reviews, 5, 177-190.

WINER, B. J. (1971). Statistical principles in experimental design (2nd ed.). New York: McGraw-Hill.

(Manuscript received August 15, 1985; revision accepted for publication November 25,1986 .) 